\title{
Target and arm observation effects on adaptation to prism displacement*
}

\author{
BENJAMIN WALLACE $\dot{\uparrow}$ \\ Western Illinois University, Macomb, Illinois 61455
}

\begin{abstract}
Adaptation to displacement of objects in the visual field was studied as a function of preexposure test targets being absent or present in that field and lateral arm movement requiring no pointing at targets being observed or unobservable during prism exposure. Significantly greater adaptation was found when targets present during prism exposure were the same as those present during pre- and postexposure test conditions. In addition, greater adaptation was found when $S$ was permitted observation of lateral arm movement during prism exposure. Greatest adaptation was produced when both targets were present and arm movement was observable during prism exposure. In addition, when three targets were present during prism exposure, the greatest amount of adaptation was found for targets on S's prismatically shifted visual field periphery.
\end{abstract}

Several investigators (Welch, 1969; Melamed, Halay, \& Gildow, 1973) have considered the role of viewing targets during prism exposure and subsequent adaptation to an optical displacement. Welch (1969) varied target specificity in an attempt to determine the nature of information from target pointing in adapting to prism viewing. His target specificity conditions during prism exposure ranged from one where $S$ was shown a visible rod at which he was asked to point and to compensate for prism-induced error to a condition where no target was available for viewing. All conditions produced significant adaptation. but it was significantly larger in the target-specified correction condition and was least in the no-target condition.

Melamed et al (1973) also studied the role of target presence in the adaptation process. However, S was required to localize three test targets before and after an exposure to eight different targets, during which $\mathrm{S}$ observed his limb moving past the exposure targets instead of pointing directly at targets during prism exposure as in the Welch (1969) study. Results showed no significant difference between a homogeneous background condition and one containing eight visible targets in the production of adaptation to a prism displacement.

The difference between the findings of Welch and Melamed et al with regard to the role of targets in the adaptation process perhaps can be accounted for by the different exposure conditions in the two studies. Welch had Ss localize the same stimulus during test situations as they observed and pointed at during prism exposure. This was not the case in the Melamed et al study.

*Part of this research was presented at the Midwestern Psychological Association convention. Chicago, 1973, and is based in part upon a dissertation submitted in partial fulfillment of the requirements for the PhD degree at Kent State University. Much appreciation is expressed to Lawrence $E$. Melamed and Katharine I. Hoyenga for comments on earlier drafts of this manuscript.

tReprint requests should be sent to Benjamin Wallace, Department of Psychology, Western Illinois University, Macomb. Illinois 61455 .
Instead, Ss were not required to point at targets during prism exposure; they were only to observe their limbs move laterally past targets. In addition, Melamed et al presented Ss with a different set of objects (eight targets) to observe during prism exposure, compared to the three targets present for localization purposes in preand postexposure test conditions. Thus, Ss in the Melamed et al study may not have associated the exposure target locations with test target locations as they perhaps did in the Welch study. If such an association is necessary to produce enhanced adaptation to visual displacement when targets are present for viewing during prism exposure, presenting the same targets in both test and exposure conditions without pointing responses during exposure may resolve the contradictory findings of the two previous studies. If a target present vs absent effect is obtained under these conditions, the failure of the effect to occur in the Melamed et al study may have been due to the use of different test and exposure targets.

Although Melamed et al did not find target presence, per se, to have an enhancing effect on adaptation magnitude, a significant interaction was found between prism-base orientation (right vs left shift) and the three test targets present in the visual field during pre- and postexposure conditions. The results of this study indicated that measurable aftereffects (the difference in pre- and postexposure judgment of location of targets) were enhanced when the test target and the direction of the lateral shift produced by the prisms were on the same side of the visual field. Thus, where base-left prisms were used, which shifted targets present in the visual field to the right of straight-ahead, greatest adaptation as measured by aftereffects was found for the right test target. Conversely, when base-right prisms were used, which shifted exposure targets in the visual field to the left of S's normal viewing, the left test target produced the greatest aftereffect. This interaction was found regardless of whether targets were absent or present 
during prism exposure. Sekuler and Bauer (1966) also considered the role of target location and prism-base orientation upon resultant adaptation to prism exposure. They found a highly significant effect of target location upon postexposure shift. With regard to this finding. it was suggested that studies dealing with specific target locations check for the possibility of interactions between the target locations and main effects. The second aim of the present study was to determine if an interaction existed between prism-base orientation and test-target location when the same targets were present during test situations as during prism exposure.

In addition to investigating the role of targets in adaptation to prism exposure, the present study also considered adaptation as a function of whether or not $\mathrm{S}$ was allowed to observe arm movement during prism exposure. McLaughlin. Rifkin, and Webster (1966) found adaptation to prismatic displacement in the absence of observed arm movement during prism exposure: Ss were only allowed to observe a visual target during optical displacement. Thus, it was pertinent to consider the role of target absence or presence in conjunction with unobservable as well as observed arm movement during prism exposure.

\section{METHOD}

Subjects

The Ss consisted of 48 right-handed undergraduate females recruited from the introductory psychology sections. Only Ss who did not wear corrective glasses were selected.

\section{Apparatus}

The apparatus used in the present study is similar to that employed and illustrated by Melamed et al (1973). The S was seated at a small wooden table with her head securely positioned on a combination head- and chinrest. Throughout all experimental conditions. S wore Risley rotating prisms attached to the front surface of welder's goggles. On the table in front of $S$ was a rectangular wooden box. $49.5 \times 77.5 \mathrm{~cm}$, open on the side facing $S$. When $S$ was asked to observe movements of her hand, it was placed in an aluminum holder running horizontally on an aluminum track on the top level of the wooden box. Immediately behind the track was a wooden blackboard that extended the entire wid th of the box. For half the Ss, a tagboard with three unnumbered targets was placed over the backboard for the entire experiment. The other half had this tagboard removed during the exposure condition and replaced with a featureless, white tagboard. The targets consisted of three black lines. $0.4 \times 15.3 \mathrm{~cm}$ and $5.1 \mathrm{~cm}$ apart, centered on the tagboard. During the pre- and postexposure test, S's hand was kept out of sight by placing it in a holder on an aluminum horizontal track similar to that used during prism exposure but located in the lower compartment (interior) of the box. This track was found directly below the one on the upper level of the box. The location of S's judgment of the three test targets, symmetrically located with respect to S's body position in pre- and postexposure conditions, was determined by reading a value from a measuring stick which was attached to the interior slide and which was, thus, moved with it.

\section{Design}

The experiment consisted of a 2 by 2 by 2 factorial design, in which target absence or presence during the prism exposure was one factor. The second factor was whether $S$ observed or did not observe lateral right-arm movements within the visual field during the exposure condition. The third factor was whether $\mathrm{S}$ wore 20-diopter binocular prisms, base right or 20-diopter binocular prisms, base left. Six Ss were randomly assigned to each of the eight groups.

\section{Procedure}

All Ss participated in a pointing accuracy task both before and after a 10 -min exposure to 20 -diopter binocular lateral prismatic displacement. The Risley prisms were set at 0 diopter for the pre- and postexposure pointing tasks. In each of these tasks, $S$ was asked to point five times, in a random order, at each of the three targets. The S's hand was on the lower compartment track and was, therefore, not visible during the pre-and postexposure conditions.

All of the experimental manipulations took place during the prism exposure period. For half the $S s$ in each of the target-absent vs target-present conditions, $S$ was able to observe her lateral arm movements by placing her index finger in the aluminum container on the top level of the wooden box. In the target-present conditions. S was not required to localize the targets; rather, these targets were merely present as S moved her limb past them. Amount of movement was controlled by asking $S$ to move her hand only within the visual field. Rate of movement was indicated and controlled by a metronome allowing $S$ to complete one cycle every $6 \mathrm{sec}$. For $S$ s not allowed to perceive arm movement, an approximation of S's visual field area was kept constant by controlling movement of S's slide. Thus. in the first few seconds during the exposure condition. S's movements were stopped by the limits of the allowable movement of the slide. When $\mathrm{S}$ hit these limits, she was told to stay within these limits and to try not to hit them or go beyond them. Furthermore, half of the target-present Ss wore 20-diopter base-right prisms and half wore 20-diopter base-left prisms during the exposure condition.

\section{RESULTS}

The dependent measure under consideration in this study was the difference in the means of S's pointing at the location of targets in the visual field as measured in the pre- and postexposure conditions.

A mixed design analysis of variance was performed with three between-S variables, target, exposure, and prism base, and one within-S variable, test target position. Two-tailed $t$ tests for correlated measures between the pre- and postexposure measures of target location were used to determine whether the negative aftereffects (see Table 1) were significantly different from zero.

There was no significant difference, $F(1,40)=2.62$, in resultant adaptation as a function of prism base (base right vs base left). Adaptation was found to be significantly different as a function of targets during the exposure condition, $F(1,40)=11.77, p<.002$. When targets were present during the exposure condition, a mean aftereffect of $5.2 \mathrm{deg}$ in the direction opposite prismatic shift was found, $\mathrm{t}(23)=8.63, \mathrm{p}<.001$. With targets absent in the exposure condition, amount of resultant adaptation was reduced to $2.5 \mathrm{deg}, \mathrm{t}(23)=$ $4.73, \mathrm{p}<.001$.

A significant difference was also found in amount of adaptation as a function of whether $S$ observed or did not observe her arm movements during the exposure condition, $F(1,40)=5.54, p<.02$. With observed arm 
Table 1

Mean Degrees Adaptation for Three Test Targets as a Function of Target Absence or Target Presence in Exposure Condition

\begin{tabular}{|c|c|c|c|c|c|c|}
\hline \multirow[b]{2}{*}{ Shift } & \multicolumn{2}{|c|}{$\begin{array}{l}\text { Adaptation for } \\
\text { Left Target }\end{array}$} & \multicolumn{2}{|c|}{$\begin{array}{l}\text { Adaptation for } \\
\text { Center Target }\end{array}$} & \multicolumn{2}{|c|}{$\begin{array}{c}\text { Adaptation for } \\
\text { Right Target }\end{array}$} \\
\hline & $\begin{array}{l}\text { Mean } \\
\text { (Deg) }\end{array}$ & SD & $\begin{array}{l}\text { Mean } \\
(\text { Deg) }\end{array}$ & SD & $\begin{array}{l}\text { Mean } \\
\text { (Deg) }\end{array}$ & SD \\
\hline \multicolumn{7}{|c|}{ Targets Absent } \\
\hline Base Right & $1.7^{*}$ & 0.78 & $2.1^{*}$ & 0.98 & $1.8^{*}$ & 1.04 \\
\hline Base Left & $2.7^{*}$ & 1.10 & $3.4^{*}$ & 1.41 & $3.2^{*}$ & 1.36 \\
\hline \multicolumn{7}{|c|}{ Targets Present } \\
\hline $\begin{array}{l}\text { Base Right } \\
\text { Base Left }\end{array}$ & $\begin{array}{l}6.1^{*} \\
5.0^{*}\end{array}$ & $\begin{array}{l}1.84 \\
1.49\end{array}$ & $\begin{array}{l}4.2^{*} \\
5.7^{*}\end{array}$ & $\begin{array}{l}1.49 \\
1.75\end{array}$ & $\begin{array}{l}3.4^{*} \\
7.2^{*}\end{array}$ & $\begin{array}{l}1.38 \\
1.98\end{array}$ \\
\hline
\end{tabular}

${ }^{*} p<.05$; analysis made by two-tailed $t$ tests for correlated measures with $d f=11$.

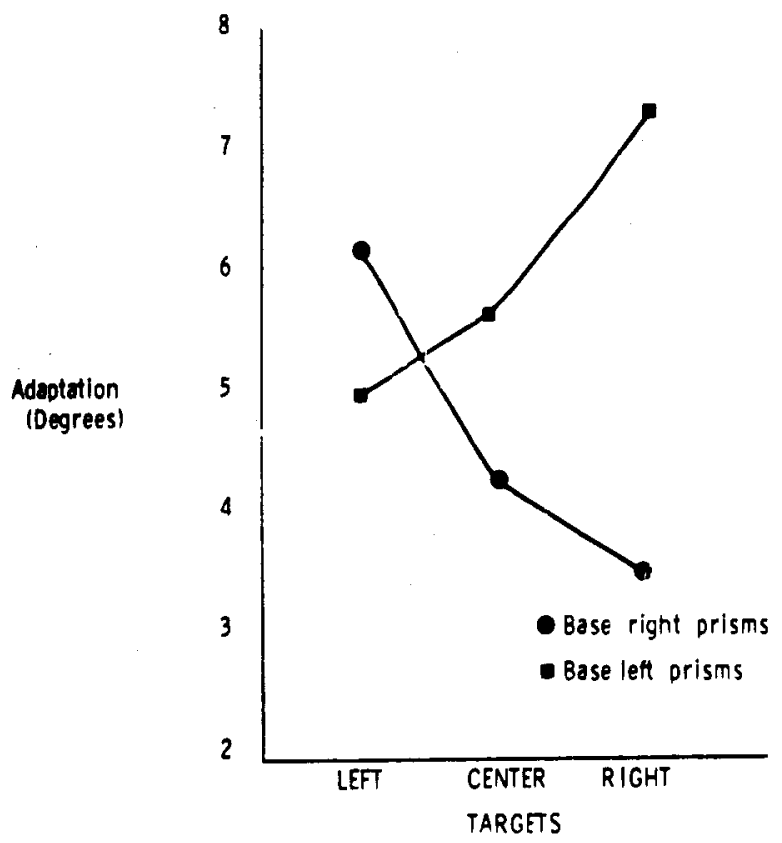

Fig. 1. Mean amount of adaptation as a function of prismatic shift and targets present in the visual field during prism exposure.

movements in the exposure condition, a mean aftereffect of $4.8 \mathrm{deg}$ was found, $\mathrm{t}(23)=7.69, \mathrm{p}<.001$. When Ss were not allowed to observe arm movement, adaptation was reduced to $2.9 \mathrm{deg}, \mathrm{t}(23)=5.82$, $\mathrm{p}<.001$.

The interaction of Targets by Exposure was not significant, $F(1,40)=0.07$. However, subsequent Newman-Keuls analyses showed amount of resultant adaptation in the target-present/unobserved-armmovement condition ( $4.4 \mathrm{deg}$ ) to be significantly greater than to the target-absent/unobserved-arm-movement condition (1.4 deg), Newmán-Keuls, $\mathrm{p}<.05$. Furthermore, a significantly greater amount of adaptation was found under observed arm movement with target presence during the exposure condition (6.1 deg) than when targets were absent (3.6 deg).
Newman-Keuls, $p<.05$. The difference in resultant adaptation to prismatic displacement between the target-absent/unobserved-arm-movement condition (1.4 deg) and the target-present/observed-arm-movement condition (6.1 deg) was also significant, Newman-Keuls, $\mathrm{p}<.01$. The difference between the target-present/unobserved-movement condition ( $4.4 \mathrm{deg}$ ) and the target-absent/observed-arm-movement condition (3.6 deg) was not significant.

Interactions between the bewteen-S variables were also found not to be significant. However, the interaction of Targets by Base Shift by Test Target Position (see Figs. 1 and 2 ) was significant, $\mathbf{F}(2,80)=$ $5.70, p<.005$. When targets were present in the visual field and displaced to the left of normal straight-ahead viewing via base-right prisms during the exposure condition (see Fig. 1), greater adaptation was found for the left, most peripherally located target of the visual field $(6.1 \mathrm{deg})$ than for the right, most centrally located target (3.4 deg), Newman-Keuls, $p<.01$. With base-left prisms, the greatest adaptation was found for the target located on the right of the visual field (7.2 deg) as compared to left-target adaptation (5.0 deg), Newman-Keuls, $p<.01$. When targets were absent during prism exposure (see Fig. 2), differential adaptation according to target location was not found. Adaptation for all targets, regardless of target absence or target presence in the visual field during the exposure condition, was still found to be significantly different from zero (see Table 1).

\section{DISCUSSION}

As the results of the present study indicate, adaptation to prismatic displacement significantly increased when targets presented during prism exposure were the same as those present during pre- and postexposure test conditions. This is in agreement with previous research (Welch, 1969), where inclusion of a visual test target during prism exposure produced greater

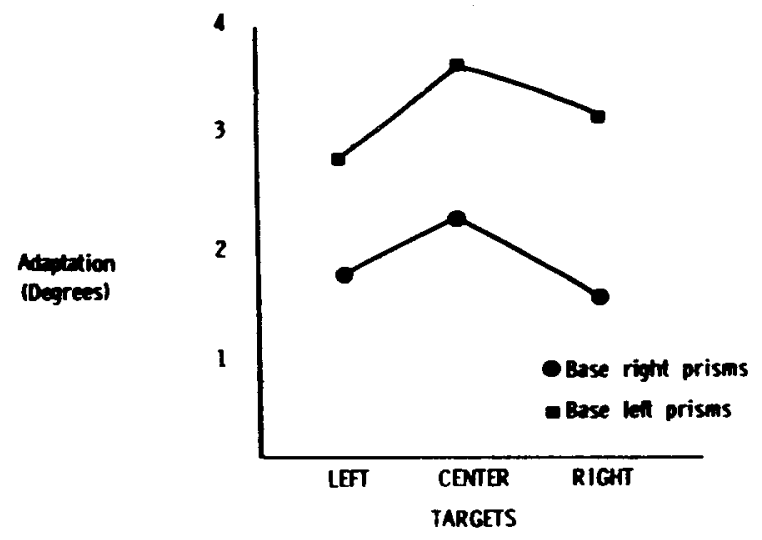

Fig. 2. Mean amount of adaptation as a function of prismatic shift and targets absent in the visual field during prism exposure. 
adaptation to visual displacement. Thus, pointing to targets during prism exposure, as in the Welch study, was not necessary to produce the target-absent vs target-present difference, while use of the same targets for test and exposure was sufficient to produce the difference. Therefore, the failure of Melamed et al to find a target-present vs target-absent difference was likely due to the use of different targets in test and exposure conditions. The findings of the present study also preclude the possibility that pointing to targets during prism exposure and the use of different test and exposure targets might also produce a difference in adaptation magnitude between targets being present and absent. Again, this is the case since target pointing during prism exposure appears not to be the critical factor in producing adaptation differences. Instead, differences in target absence and presence appear to be primarily a function of using the same targets during test and exposure conditions.

When targets were absent during prism exposure but arm movement was observable, adaptation still was found in the present study. This is in agreement with previous research (Held \& Gottlieb, 1958; Held \& Schlank, 1959), where observed active arm movement during prism exposure was considered a requisite for the production of adaptation to a prism displacement. However, significant adaptation was still found in the present study and in the McLaughlin et al (1966) study whether $\mathrm{S}$ observed or did not observe arm movement during prism exposure, although significantly greater adaptation was found in the present study for observed arm movement compared to unobservable arm movement. Therefore, although adaptation is best with viewed, active arm movement (Held, 1961), it still occurs in the absence of such viewed movement.

If arm movement is not observable during prism exposure, $\mathrm{S}$ can still test felt arm location with respect to targets if they are present for viewing during the exposure. Thus, felt-arm-location testing may be sufficient for creating a discrepancy between the felt arm location and observable target location during prism exposure. Also, Welch (1969) felt that in a homogeneous background condition, as in previous studies (Held \& Gottlieb, 1958; Held \& Schlank, 1959) where S could observe arm movements during prism exposure, $\mathrm{S}$ could relate the image of his arm to the border of the visual field. Thus, this may have served a significant role in the adaptation process. If this additional source of information is salient for $S$ in detecting the existence of a discrepancy in actual and apparent location of targets with respect to arm location, one would expect the greatest magnitude of adaptation to occur when targets were present and arm movement was perceived during the exposure condition, since under such a situation produced information in the form of discrepancies is quite extensive. The results of the present study show adaptation to be greatest in such a situation. With sources of information reduced concerning the presence of a discrepancy, amount of resultant adaptation decreased. The preceding interpretation of the results of the present study is also in agreement with recent findings reported by Uhlarik (1973), where when several sources of information were available to Ss during exposure to rearrangement indicating a discrepancy in the location of targets, adaptation was greater in magnitude than when discrepant sources of information were reduced.

The interaction of prism base orientation and target location found by Melamed et al (1973) was also found in the present study. However, this was only the case if targets were present for viewing during prism exposure. Since Melamed et al used different test and exposure targets, whereas the present study used the same targets during test and exposure conditions, it must be concluded that the prism orientation and target location interaction occurs regardless of whether test and exposure targets are the same or different. The possible reasons for the failure of the present study to replicate the Melamed et al interaction of prism orientation and test target location during target absence cannot be determined from a comparison of the methodologies of the two studies, since both studies used the same procedures, as far as can be determined, in the target-absent exposure condition.

\section{REFERENCES}

Held, R. Exposure history as a factor in maintaining stability of perception and coordination. Journal of Nervous \& Mental Diseases, 1961, 132, 26-32.

Held, R., \& Gottlieb, N. Technique for studying adaptation to disarranged eye-hand coordination. Perceptual \& Motor Skills, $1958,8,83-86$.

Held, R., \& Schlank, M. Adaptation to disarranged eye-hand coordination in the distance dimension. American Journal of Psychology, 1959, 72,603-605.

McLaughlin, S. C., Rifkin, K. I., \& Webster, R. G. Oculomotor adaptation to wedge prisms $w i t h$ no part of the body seen. Perception \& Psychophysics, $1966,1,452-458$.

Melamed, L. E., Halay, M., \& Gildow, J. An examination of the role of task oriented attention in the use of active and passive movement in visual adaptation. Joumal of Experimental Psychology, 1973, 98, 125-130.

Sekuler, R. M., \& Bauer, J. A., Jr. Adaptation to prismatic displacement: Hand position and target location. Journal of Experimental Psychology, 1966, 72, 207-212.

Uhlarik, J. J. Role of cognitive factors on adaptation to prismatic displacement. Journal of Experimental Psychology, $1973,98,223-232$.

Welch, R. B. Adaptation to prism-displaced vision: The importance of target pointing. Perception \& Psychophysics, $1969,5,305-309$.

(Received for publication July 9, 1973; revision received October $18,1973$. 